\title{
Psychological distress and self-harm in a religiously diverse sample of Lebanese students
}

\author{
Moubadda Assi, Ismael Maatouk \& Rusi Jaspal \\ Nottingham Trent University
}

\begin{abstract}
Drawing on identity process theory from social psychology, this study explores the protective and risk factors of psychological distress and self-harm in a religiously diverse sample of heterosexual and non-heterosexual students at an English-speaking university in Lebanon. A convenience sample of 209 undergraduate students participated in a cross-sectional survey and completed measures of religiosity, identity threat, psychological distress and self-harm. Results indicated that non-heterosexual participants exhibited higher levels of psychological distress, were more likely to report self-harm, and reported lower levels of religiosity than their heterosexual counterparts. The multiple regression analyses showed that religiosity is protective against psychological distress, and that sexual orientation distress predicts selfharm. In order to reduce the risk of psychological distress and self-harm, it will be necessary to challenge stigma towards sexual minorities, to promote engagement with a broader range of social identity categories (other than just religion), and to ensure that individuals of all faiths and sexualities in Lebanon are able to access counselling support if they require it.
\end{abstract}

\section{Keywords}

psychological distress; self-harm; religiosity; sexual orientation; Lebanon

\section{Correspondence}

Professor Rusi Jaspal, School of Social Sciences, Nottingham Trent University, Nottingham NG1-4FQ, United Kingdom. E-mail: rusi.jaspal@ cantab.net 


\title{
Psychological distress and self-harm in a religiously diverse sample of Lebanese students
}

\begin{abstract}
Drawing on identity process theory from social psychology, this study explores the protective and risk factors of psychological distress and self-harm in a religiously diverse sample of heterosexual and non-heterosexual students at an English-speaking university in Lebanon. A convenience sample of 209 undergraduate students participated in a cross-sectional survey and completed measures of religiosity, identity threat, psychological distress and self-harm. Results indicated that non-heterosexual participants exhibited higher levels of psychological distress, were more likely to report self-harm, and reported lower levels of religiosity than their heterosexual counterparts. The multiple regression analyses showed that religiosity is protective against psychological distress, and that sexual orientation distress predicts selfharm. In order to reduce the risk of psychological distress and self-harm, it will be necessary to challenge stigma towards sexual minorities, to promote engagement with a broader range of social identity categories (other than just religion), and to ensure that individuals of all faiths and sexualities in Lebanon are able to access counselling support if they require it.
\end{abstract}

\section{Keywords}

psychological distress; self-harm; religiosity; sexual orientation; Lebanon

\section{Introduction}

Psychological distress and self-harm are indicative of poor mental health. People who experience these forms of psychological adversity are more likely to engage in behaviours that put their health and wellbeing at risk, such as alcohol and substance misuse and sexual risk behaviours (Shuper et al., 2010). In many cases, there are preventable social psychological antecedents to psychological distress and self-harm, such as stigma, rejection and discrimination (Jaspal, Lopes \& Rehman, 2019). It is therefore important to understand the socio-cultural context in which individuals facing, or at risk of, these forms of psychological adversity are located. For instance, for many people of religious faith, their religion constitutes an important meaning system and a significant group membership - thus, rejection from this group can be psychologically distressing (Schluderman et al., 2001). There is evidence that both psychological distress and self-harm are more prevalent in nonheterosexual people than in the general population (Liu \& Mustanski, 2012; Mustanski, Garofolo \& Emerson, 2010). However, there is a paucity of data on the social psychological underpinnings of psychological distress and self-harm in the religiously diverse society of Lebanon. Accordingly, this preliminary study attempts to address this gap by exploring the protective and risk factors of psychological distress and self-harm in a religiously diverse sample of heterosexual and non-heterosexual students at an English-speaking university in Lebanon.

\section{Lebanese society}

Lebanon is a diverse country which is home to various religious groups, including Christian Maronite, Greek Catholic and Greek Orthodox, Sunni and Shia Muslim, and Druze communities. Intergroup relations between these diverse religious communities have long been tense, and these tensions culminated in a bitter and bloody civil war between 1975 and 1990, in which over 90,000 people lost their lives (Labaki, 1994). The Lebanese Civil War radically changed the demographic profile of Lebanon, and weakened both the stability and primacy of Lebanese national identity over competing social identities, namely religion. The primacy of religious identity in Lebanon has led to the salience of distinct norms, values and 
representations perceived to be associated with one's religion (Maatouk and Jaspal, 2019). Religion tends to constitute an important social identity, that is, group membership, which also provides a significant source of meaning for many Lebanese people (Harb \& Smith, 2008).

Although Lebanon can be regarded as one of the more socially liberal societies in the Middle East, it is also a collectivist society in which religious and cultural norms prevail. Young people in Lebanon face family, cultural and religious pressures to conform to dominant norms and may experience rejection and stigma if these norms are violated. Indeed, across all religious groups in Lebanon, the family ranks very highly as a primary social institution (Kazarian, 2005). This may entail the regulation of sexuality, for instance. Indeed, both Lebanese law and social attitudes tend to take a negative stance on sexual diversity, such as non-heterosexual identities (Obeid et al., 2020). According to Article 534 of the Lebanese Penal Code of 1943, sexual relations which 'contradict the law of nature' are prohibited by law, and those found guilty of this offence (which can include homosexual relations) can face up to a year in prison (Human Rights Watch, 2018; Makarem, 2012). Although this law is not widely enforced, there is evidence that social attitudes towards homosexuality are generally negative (Obeid et al., 2020), which in turn may lead non-heterosexual Lebanese people to experience negative mental health outcomes, such as psychological distress and self-harm.

\section{Psychological distress}

Psychological distress can be defined as 'unpleasant emotional experience of a psychological (i.e. cognitive, behavioural, emotional) and/or social nature that interferes with an individual's ability to effectively cope with a given situation' (Sellick \& Edwardson, 2007, p. 535). According to identity process theory (Breakwell, 1986; Jaspal \& Breakwell, 2014), psychological distress can arise when individuals experience 'threats' to their identity, that is, decreased feelings of self-esteem, continuity, self-efficacy and distinctiveness. This form of psychological adversity has significant implications for physical and psychological health (Ozbay et al., 2007). Studies have generally revealed a relatively high prevalence of psychological disorders, such as anxiety and mood disorders in Lebanon, but that only a minority receive formal treatment for these disorders (Karam et al., 2006; Karam et al., 2008). Wehbe (2011) has found that self-stigma is a significant predictor of attitudes towards psychological counselling among Lebanese students.

The available evidence suggests that women in Lebanon are especially prone to psychological distress. In their study of young people in Lebanon, Ayyash-Abdo and Alamuddin (2007) found that men exhibited higher positive affect than women and that socio-economic status was predictive of subjective wellbeing. Furthermore, in their study of three samples of Lebanese young adults, Barbour, Saadeh and Salameh (2012) found that women were more susceptible to psychological distress than men (see also Ammar, Nauffal $\&$ Sbeity, 2013). There has been some work on the impact of violence on psychological health, including the onset of psychological distress (e.g. Abu-Saba, 1999; Itani, Fischer and $\mathrm{Chu}, 2018)$. Although there is no research into psychological distress among nonheterosexual people in Lebanon, there is evidence from other countries that non-heterosexual people are at increased risk of psychological distress, due largely to preventable situational stressors.

\section{Self-harm}

There has been only limited research into suicidal ideation in Lebanon (Baroud et al., 2019; El Majzoub et al., 2018), with some work focusing on specific groups, such as patients with chronic illness (Macaron et al., 2014). However, there has been no systematic research into self-harm in Lebanon in the Lebanese population. Much of the available evidence originates 
from the US and other Western societies, whose transferability to the Lebanese context is unclear. This research suggests that the majority of self-harmers who present to hospitals are diagnosed with at least one psychiatric disorder, most commonly depression followed by substance abuse and anxiety disorders (Haw et al., 2001). Moreover, it appears that key risk factors for self-harm include young age, non-heterosexuality and psychological disorders while potential protective factors include religious affiliation and cultural norms (Skegg, 2005).

A systematic review including data from 214,344 heterosexuals and 11,971 nonheterosexuals revealed a higher risk of mental disorder and deliberate self-harm among nonheterosexuals (King et al., 2008). Self-harm among sexual minorities is reportedly driven by various stressors including disclosure within homophobic environments (DiStefano, 2008). A qualitative study among 39 Japanese gay men revealed that sexual minority suicidality and self-harm were attributable in part to verbal, psychological, sexual, or physical violence, including bullying and ostracism from the family or workplace upon disclosure of one's sexual orientation. In a US school-based survey, non-heterosexual youths were more likely to report self-harm than heterosexuals (Almeida et al., 2009). In their cross-sectional study, Rehman, Lopes and Jaspal (2020) found that situational stressors, such as discrimination, victimisation and internalised homophobia put non-heterosexual people at risk of self-harm. Self-harm may be regarded as a maladaptive coping behaviour which arises as a result of exposure to distressing psychological experiences when other adaptive strategies are less available (McMahon et al., 2013).

\section{Religious identity}

Religiosity is conceptualised as the strength of connection with both one's faith and with other members of one's religious group (Plante et al., 2002). There is cross-cultural evidence that religiosity can be protective against poor mental health, including in Lebanon (Khamis, 2012).

Ghandour, Karam and Maalouf (2009) found that religiosity (that is, belief in God and religious practice) was inversely associated with the onset of alcohol-related problems, as defined by the Diagnostic and Statistical Manual of Mental Disorders (DSM), across all religious groups in Lebanon, although the effect was strongest for Muslims. Furthermore, religiosity has been found to constitute a protective factor against severe gambling behaviour, which can be or become pathological (Ghandour and El Sayed, 2013). There is evidence that religiosity is a moderator of the relationship between adverse events (e.g. bullying) and poor mental health outcomes (e.g. substance misuse) in Lebanese young people, with those who are more religious being less likely to engage in substance misuse (Afifi et al., 2020).

In view of the armed conflicts experienced in the Lebanese population, there has also been work on the role of religiosity in response to conflict-related psychological adversity. Farhood and Dimassi (2012) found that social support (partly in the form of religious involvement) was protective against post-traumatic stress disorder and depression in six villages in South Lebanon, which had seen considerable conflict in the years that preceded the study (see also Khaamis, 2012). In their preliminary investigation of 74 Lebanese students, Moussa and Bates (2011) found that religious coping strategy predicted posttraumatic growth, suggesting that religion can provide the psychological resources for minimising the adverse effects of stressful events.

Although the protective effects of religion in the face of poor mental health have been established in older Lebanese people (Chaaya et al., 2007), it is unclear whether this effect is also true in younger samples of Lebanese people of diverse sexual orientations. In view of the negative social attitudes towards non-heterosexual people in Lebanon (Obeid et al., 2020) and the powerful anti-gay rhetoric associated with religious leaders (Maatouk \& Jaspal, 
2020), it is unlikely that non-heterosexual Lebanese people exhibit high levels of religiosity or that religion functions in a protective manner.

\section{Hypotheses}

1. Heterosexuals will exhibit higher levels of religiosity, and higher levels of psychological wellbeing than non-heterosexuals.

2. Non-heterosexuals are more likely than heterosexuals to self-harm.

3. Identity threat and sexual orientation predict psychological distress, while religiosity is protective against it.

\section{Ethics}

\section{Methods}

The Health and Life Sciences Faculty Research Ethics Committee at De Montfort University, Leicester, UK provided ethical approval for this study.

\section{Participants}

A sample of 209 undergraduate students at a university in Beirut, Lebanon participated in a survey study of psychological distress and self-harm. Participants were aged between 18 and 36 years $(M=21, S D=2.45)$. There were 135 females (64\%), 69 males $(33 \%)$, and 5 gender non-binary individuals $(2 \%)$. There were $140(67 \%)$ heterosexuals and $66(32 \%)$ nonheterosexuals - non-heterosexuals identified as bisexual $(N=39,19 \%)$, gay $(N=18,9 \%)$, other $(N=7,2 \%)$, and lesbian $(N=9,4 \%)$. The majority of participants reported Lebanese nationality $(N=197,94 \%) ; 4(1.9 \%)$ reported Palestinian nationality; $2(1 \%)$ Syrian nationality and 6 (2.9\%) other Arab nationality. There were 121 (58\%) Christians and 66 (32\%) Muslims more specifically, 75 respondents (36\%) described themselves as Christian Maronite, 40 (19\%) as Sunni Muslim, 29 (14\%) as Catholic, $26(12 \%)$ as Shia Muslim, $17(8 \%)$ as Greek Orthodox, $12(6 \%)$ as Druze and $10(5 \%)$ as Other. Table 1 provides a full description of the participant sample.

***Insert Table 1 here**

\section{Measures}

Religiosity was measured using the 5-item Abbreviated Santa Clara Strength of Religious Faith Questionnaire (Plante et al., 2002) which included items such as "I enjoy being around others who share my faith". The items were measured on a 4-point scale (1=strongly disagree to $4=$ strongly agree). The higher the score, the higher the level of religiosity $(\alpha=.9)$.

Identity threat was measured using the 5-item Identity Principles Scale (Murtagh, Gatersleben \& Uzzell, 2014) focusing on individual's overall perceptions of the identity principles (selfefficacy, self-esteem, continuity, and distinctiveness). Items included "I have not changed in time" (continuity) and "I see myself as someone who has high self-esteem" (self-esteem). The items were measured on a 5-point scale ( $1=$ not true of me to $5=$ very true of me). Items were reversed scored as, in identity process theory, low levels of the identity principles are conceptualised as identity threat. A mean score was calculated to produce an overall score of identity threat - the higher the score, the more threatened identity was $(\alpha=.69)$.

Psychological distress was measured using the 18-item Brief Symptom Inventory (Derogatis, 2001). Items included physical symptoms of depression, anxiety and stress, e.g. "Faintness or dizziness"; psychological symptoms of anxiety/ panic and stress, e.g. "Feeling no interest on things"; and suicidal ideation "Thoughts of ending your life". Items were measured on a 5- 
point scale ( $1=$ not at all to $5=$ extremely). The higher the score, the more psychological distress $(\alpha=.94)$.

Self-harm was measured using the following item from the Adult Psychiatric Morbidity Survey (McManus et al., 2016): "Have you ever deliberately harmed yourself in any way but not with the intention of killing yourself?" Possible responses were 'yes' or 'no'.

\section{Statistical analyses}

SPSS version 26 was used to perform the analyses. First, independent samples $t$-tests bootstrapped at 1000 samples to control for statistical power were performed to analyse differences between the main groups in the sample (gender: male vs. female; religion: Christian vs Muslim; and sexual orientation: heterosexual vs. non-heterosexual) for the key variables. Cohen's ds and 95\% Confidence Intervals (CIs) were reported to control for the strength of between group mean differences for the key variables. Second, chi-squared tests bootstrapped at 1000 samples were performed to test associations between categorical variables. The Phi values were reported to examine effect sizes of chi-squared relationships. Third, stepwise regressions were conducted with a bootstrap set at 1000 samples to test which variables predicted psychological distress and self-harm, respectively.

\section{Descriptive statistics}

\section{Results}

Table 2 provides a full summary of the descriptive statistics concerning the key variables of interest. The mean scores for religiosity was $2.35(S D=1.19)$. In contrast, the mean score for identity threat was relatively high, $M=3.0, S D=.83$. Furthermore, the mean for psychological distress was $1.8(S D=.98)$, suggesting moderate psychological distress in the sample, and 106 (51\%) participants reported self-harm while $103(49 \%)$ reported no self-harm, suggesting a very high prevalence of self-harm in this sample.

$$
\text { **Insert Table } 2 \text { here** }
$$

\section{Between group differences for religiosity}

Independent samples $t$-tests showed statistically significant differences between males and females for religiosity $[t(202)=-1.998, p<.05$; Cohen's $d=0.2 ; 95 \%$ CIs $(.69748, .00461)]$. Females $(M=2.48, S D=1.71)$ were more religious than males $(M=2.13, S D=1.22)$.

Further independent samples $t$-tests showed statistically significant differences between heterosexuals and non-heterosexuals for religiosity $[t(205)=5.569, p<.001$; Cohen's $d=0.5 ; 95 \%$ CIs $(.27534, .95467]$. Heterosexuals $(M=2.45, S D=1.27)$ showed higher levels of religiosity than non-heterosexuals $(M=1.92, S D=.87)$.

There were no statistically significant effects of religious group or relationship status on levels of religiosity $(p>0.5)$.

\section{Between group differences for identity threat and psychological distress}

Independent samples $t$-tests showed a statistically significant difference between males and females for identity threat $[t(202)=-3.273, p=.001$; Cohen's $d=0.1 ; 95 \%$ CIs $(-.62821$, $.15581)]$ but not for psychological distress $(p>0.5)$. Generally, females showed high levels of identity threat $(M=3.09, S D=.81)$ than males $(M=2.70, S D=.80)$.

Further independent samples $t$-tests showed a statistically significant difference between heterosexuals and non-heterosexual for psychological distress $[t(205)=-3.250$, $p=.001$; Cohen's $d=0.4 ; 95 \%$ CIs $(-.75229,-.18413)]$ but not for identity threat $(p>0.5)$. Non- 
heterosexuals $(M=2.0, S D=.9)$ showed higher levels of psychological distress than heterosexuals $(M=1.53, S D=1.0)$.

Independent samples $t$-tested exhibited a statistically significant difference between Christians and Muslims for psychological distress $[t(185)=-2.131, p=.001$; Cohen's $d=0.3$; $95 \%$ CIs (-.61546, -.02366)] but not for identity threat $(p>0.5)$. On the whole, Muslims $(M=1.88, S D=1.1)$ reported higher psychological distress than Christians $(M=1.56, S D=.91)$.

\section{Effects of gender, religion and sexual orientation on self-harm}

An chi-squared test showed an effect of sexual orientation (heterosexual vs. nonheterosexual) on self-harm (no self-harm vs. self-harm $\left[\chi^{2}(1,207)=4.164, p<.05 ;\right.$ Phi=.142, $p<.05]$. More non-heterosexuals reported self-harm $(N=40,60 \%)$ than those who did not $(N=26,39 \%)$. In contrast, more heterosexuals reported no self-harm $(N=77,66 \%)$ than those who did $(n=40,34 \%)$. This suggested that non-heterosexuals were more vulnerable to selfharm than heterosexuals. There was no statistically significant impact of gender or religious group on self-harm $(p>0.5)$

\section{Differences between self-harm vs. non-self-harm groups}

Independent samples $t$-tests showed a statistically significant difference between those who reported self-harm vs. those who reported no self-harm for psychological distress $[t(207)=-$ 5.317, $p=.001$; Cohen's $d=0.7 ; 95 \%$ CIs (-.93323, -.42837)] only and no effects for religiosity or identity threat $(p>.05)$. Students who reported self-harm $(M=2.01, S D=.93)$ exhibited more psychological distress than those who reported no self-harm $(M=1.33$, $S D=.92)$.

\section{Correlations}

Generally, the results indicated positive correlations between identity threat and psychological distress $[r(209)=.28, p<.001]$. Moreover there were negative correlations between religiosity and psychological distress $[r(209)=.24, p<.001]$ and between religiosity and identity threat $[r(209)=.20, p<.005]$.

$$
\text { **Insert Table } 3 \text { here** }
$$

\section{Two-way ANOVA}

A median split was performed on the religiosity variable to dichotomise it into high vs. low religiosity. This was followed by a two-way ANOVA to explore the interaction of religiosity and sexual orientation in the prediction of psychological distress. The overall model successfully predicted $5.4 \%$ of the variability in psychological distress $(\mathrm{F}=2.30 ; p<.05)$. Sexual orientation was significantly associated with psychological distress $(\mathrm{F}=2.71 ; p<.05)$ whereas religiosity and its interaction with sexual orientation were not $(p>.05)$. This suggested that, irrespective of levels of religiosity, non-heterosexuals were at greater risk of psychological distress than heterosexuals.

\section{Multiple regression models}

As self-harm and psychological distress represent distinct dimensions of mental health: behavioural and cognitive-affective, respectively, two separate multiple regressions were conducted to predict these variables.

First, a binary logistic regression was conducted to examine which variables predicted the variance of self-harm. The variables of sexual orientation and religiosity were inserted as predictors, and self-harm was inserted as the dependent variable. The binary logistic regression model was statistically significant for self-harm $\chi^{2}(2)=7.74, p=.02$. The model 
explained $4.9 \%$ of the variance in self-harm and correctly classified $56.5 \%$ of cases. Out of the predictors, only sexual orientation had predictive power for self-harm with a $\beta=.30$, Wald $=6.39, p<.05$, suggesting that sexual orientation was associated with increased likelihood of self-harm in our sample.

Second, a multiple stepwise regression was conducted to examine which variables predicted the variance of psychological stress. The variables of religious group; sexual orientation; identity threat; and religiosity were inserted as predictors, and psychological distress was inserted as the dependent variable.

Identity threat was entered into Step 1 and explained $7.5 \%$ of the variance in psychological distress. At Step 2, identity threat and religiosity explained $10.6 \%$ of the variance in psychological distress. R-square change was 0.035 and F-change was 8.260 $(\mathrm{p}=0.004)$. At Step 3, identity threat, sexual orientation and religiosity explained $11.9 \%$ of the variance in psychological distress. R-square change was 0.017 and F-change was 4.097 $(\mathrm{p}=0.044)$. The regression model was statistically significant for psychological distress $[F(1$, $\left.205)=4.097, p<.05 ; R^{2}=.119\right]$. Of all predictors, identity threat with a $\beta=.234$ S.E. $=.079,95 \%$ CIs $(.122, .435)(t=3.513, p=.001)$ was the most powerful, followed by sexual orientation with a $\beta=.134$, S.E. $=.051,95 \%$ CIs $(.003, .204)(t=2.024, p<.05)$ and religiosity with a $\beta=-$ .172 , S.E. $=.056,95 \%$ CIs $(.-.252,-.033)(t=2.568, p=.011)$ had significant effects on the variance of psychological distress. The variable of religious group was excluded from the model in the 3 steps.

\section{Discussion}

While there has been some investigation of psychological distress in the Lebanese population, there has been very limited research into self-harm and none that focuses on these mental health indicators specifically among non-heterosexual people in Lebanon. This preliminary study sheds some light on psychological distress and self-harm in this population and the possible protective factor of religiosity. Overall, our findings supported the three hypotheses. Heterosexuals exhibited higher levels of religiosity, and higher levels of psychological wellbeing than non-heterosexuals. Sexual orientation predicted the variance of self-harm, with non-heterosexuals being more likely to self-harm. Identity threat and sexual orientation predicted psychological distress, while religiosity was protective against it.

Poor mental health among university students is a global concern resulting in cognitive but also behavioural outcomes, notably self-harm (Storrie et al., 2010). As in global findings, our data from Lebanese university students showed a high prevalence of self-harm. Progression through academic study, increased workload, and financial pressures are thought to increase psychological stress and decrease opportunities to develop protective factors for poor mental health (Macaskill, 2013). In addition to these pervasive stressors, the conservative culture of Lebanon does not generally favour help-seeking which can lead people to rely on less effective coping strategies, such as self-harm, to seek respite from psychological adversity.

Previous research has generally indicated that women are at greater risk of psychological distress than men (Nauffal, Ammar \& Sbeity, 2013; Barbour, Saadeh \& Salameh, 2012), which has been attributed to the patriarchal nature of Lebanese society and pervasive gender inequality (Ayyash-Abdo \& Alamuddin, 2007). However, our study of Lebanese students did not reveal this gender difference. Furthermore, women were no more likely than men to engage in self-harm behaviour, which is inconsistent with research conducted in other contexts (e.g. Hawton et al., 2002). This could be attributed to the fact that all of the participants were university students, of a relatively high socio-economic background given the nature of the educational institution at which they were studying and, thus, arguably less susceptible to patriarchy and inequality based on gender (Botticello, 
2009). This demonstrates the importance of recognising the heterogeneity of Lebanese society in research - especially in terms of socio-economic differences. Unlike previous research (e.g. Ayyash-Abdo \& Alamuddin, 2007), ours revealed a difference in levels of psychological distress between Muslim and Christian participants, with Muslim participants exhibiting greater proneness to it. The social psychological underpinnings of this higher proclivity to psychological distress will need to be investigated further but it is possible that the strict norms, religious expectations and the regulation of lifestyle in Lebanese Muslim families present challenges for young students in secular university settings (Ghandour, Karam \& Maalouf, 2009).

One key difference in this study was between heterosexual and non-heterosexual students, with the latter being more susceptible to both psychological distress and self-harm than their heterosexual counterparts (see also Marshall et al., 2011). Although the underpinnings of psychological distress and self-harm were not the key focus of this study, previous research highlights the insidious effects of situational stressors, such as sexual orientation stigma, on mental health outcomes, including psychological distress and selfharm (Almeida et al., 2009; Jaspal, Lopes \& Rehman, 2019; Rehman, Lopes \& Jaspal, 2020). In view of the negative social attitudes towards sexual minorities in Lebanon (Obeid et al., 2020), which are often reinforced by both legislation and religious discourses against sexual minorities (Human Rights Watch, 2018; Makarem, 2012), it is likely that these situational stressors are more acutely experienced by non-heterosexual people in Lebanon than by those in Western countries, for instance. It is, however, acknowledged that Lebanon is more socially liberal than many other countries in the Middle East (Maatouk \& Jaspal, 2020). Moreover, non-heterosexual people are less likely to be open about their sexual orientation due to anticipated prejudice, which may add a further layer of complexity to their identities as they are compelled to conceal their identities and to feign heterosexuality in some contexts. Overall, these social and psychological stressors may culminate in psychological distress.

Consistent with much previous research in Lebanon (Afifi et al., 2020; Moussa \& Bates, 2011), our findings suggested that religiosity was protective against psychological distress, that is, the more religious one is (in terms of both spirituality and religious participation), the less likely one is to experience psychological distress. Indeed, the spirituality component of religiosity can provide meaning, hope and optimism (Meanley, Pingel \& Bauermeister, 2016), while religious participation and identification with other members of one's religious group provide a structured social identity, social support and motivation (Greenfield \& Marks, 2007). Therefore, religiosity may provide access to effective strategies for coping with psychological adversity and, as a robust social group membership, enhance mental health (Sani et al., 2012). Religiosity may be especially effective in societies, such as that of Lebanon, in which religious identity has primacy over other identities (Harb \& Smith, 2008).

Yet, it is clear that religiosity is not universally protective. Our results showed that non-heterosexual people exhibited lower levels of religiosity than their heterosexual counterparts. This may be attributed to the perception among non-heterosexual people that they are not accepted by their religious groups (itself a product of the heteronormativity and homophobia sometimes observable in religious discourses). In social identity theory, this has been referred to as the 'exit option' (Tajfel, 1981), that is, self-removal from social groups that cause psychological distress. Use of this strategy may limit rejection from one's religious group, but our data suggested that this did not necessarily limit the extent of psychological distress since individuals also lose access to a potentially effective protective strategy. Identity process theory (Breakwell, 1986) describes a series of coping strategies that may be used in response to threat and distress - some adaptive and others maladaptive. For many, 
identification with religion does constitute an adaptive coping strategy (Moussa \& Bates, 2011).

The results showed that sexual orientation predicted self-harm behaviours in participants, suggesting that this population, already more prone to psychological distress, was also at risk of self-harm. Indeed, McDermott et al. (2008) found that sexual minorities may feel unable to access social support and, thus, employ individual maladaptive strategies for reducing feelings of shame related to their stigmatised sexual orientation - one such strategy is self-harm. This may explain the susceptibility of non-heterosexual people in our sample to self-harm.

\section{Limitations}

This preliminary study has several limitations which should be addressed in future research. First, the study did not measure the specific situational antecedents of psychological distress in the sample. Having established differences between heterosexual and non-heterosexual people in Lebanon, we believe that future research should focus on these antecedents in nonheterosexual people specifically. Second, the cross-sectional design of this study removes the possibility of unequivocal conclusions about causality (e.g. does salience of religious identity reduce psychological distress?). Future research should use experimental manipulations of religious salience to test causal hypotheses, for which this study provides robust foundations. Third, although the single item used to measure non-suicidal self-harm was clear, it does capture a variety of behaviours that might be understood to constitute self-harm. Given the high prevalence of self-harm in the sample, future research ought to focus on effective measurement of this variable by attempting to capture the different types of self-harm behaviour. On a related note, self-harm was measured in this preliminary study but future research should also include suicidal ideation and suicide attempts. Fourth, this study sampled a relatively high number of non-heterosexuals with low reported numbers of lesbians. A convenience sample was recruited from the university social club focussing on sexual minorities which could explain the observed skew. This preliminary study on selfharm looked to detect differences between heterosexuals and non-heterosexuals but future research should explore deeper variations across sexual identity categories, such as gay, lesbian, and bisexual. Fifth, the results of this study are not transferrable to the general population because of the sampling approach. The English-language questionnaire was administered to students at an English-speaking university, which may be atypical of the Lebanese general population.

\section{Conclusions}

This preliminary study provides novel insights into psychological distress and self-harm in a religiously diverse sample of heterosexual and non-heterosexual students at an Englishspeaking university in Lebanon. It is shown that non-heterosexual people are more susceptible to psychological distress and self-harm, and exhibit lower levels of religiosity than their heterosexual counterparts. Unlike Western societies, religious identities in the collectivist Lebanese society are central to people lives: they are not just personal beliefs, but rather they reflect a group membership, a community, a history, and a political identity and, for some, constitute a protective factor (Maatouk and Jaspal, 2020). In order to ensure the wellbeing of the diverse population of Lebanon, it is important to challenge stigma towards sexual minorities - especially in religious contexts, to promote engagement with a broader range of social identity categories (other than just religion), and to ensure that individuals of all faiths and sexualities are able to access effective counselling support if they require it. These steps will undoubtedly contribute to tackling the significant challenges of psychological distress and self-harm in the Lebanese population. 


\section{References}

Abu-Saba, M. B. (1999). War-related trauma and stress characteristics of American university of Beirut students. Journal of Traumatic Stress, 12(1), 201-207.

https://doi.org/10.1023/A:1024766920789

Afifi, R. A., El Asmar, K., Bteddini, D., Assi, M., Yassin, N., Bitar, S., \& Ghandour, L. (2020) Bullying victimization and use of substances in high school: does religiosity moderate the association? Journal of Religion and Health, 59, 334-350.

https://doi.org/10.1007/s10943-019-00789-8

Almeida, J., Johnson, R. M., Corliss, H. L., Molnar, B. E., \& Azrael, D. (2009). Emotional distress among LGBT youth: the influence of perceived discrimination based on sexual orientation. Journal of Youth and Adolescence, 38(7), 1001-1014.

https://doi.org/10.1007/s10964-009-9397-9

Ayyash-Abdo, H., \& Alamuddin, R. (2007). Predictors of subjective well-being among college youth in Lebanon. The Journal of Social Psychology, 147(3), 265-284.

https://doi.org/10.3200/SOCP.147.3.265-284

Barbour, B., Saadeh, N., Salameh, P.R. (2012) Psychological distress in Lebanese young adults: constructing the screening tool 'BDS-22'. International Journal of Culture and Mental Health, 5(2), 94-108. https://doi.org/10.1080/17542863.2011.563043

Baroud, E., Ghandour, L. A., Alrojolah, L., Zeinoun, P., Maalouf, F. T. (2019). Suicidality among Lebanese adolescents: prevalence, predictors and service utilization. Psychiatry Research, 275, 338-344. https://doi.org/10.1016/j.psychres.2019.03.033

Botticello, A. L. (2009). A multilevel analysis of gender differences in psychological distress over time. Journal of Research on Adolescence, 19, 217-247. https://doi.org/10.1111/j.15327795.2009.00591.x

Breakwell, G. M. (1986). Coping with Threatened Identities. London: Methuen.

Chaaya, M., Sibai, A. M., Fayad, R., \& Roueiheb, Z. (2007) Religiosity and elderly depression: evidence from refugee and non-refugee underprivileged urban communities. Aging and Mental Health, 11(1), 37-44. https://doi.org/10.1080/13607860600735812 Derogatis, L. R. (2001). BSI 18, Brief Symptom Inventory 18: Administration, scoring and procedures manual. NCS Pearson, Incorporated. https://doi.org/10.1037/t07502-000 DiStefano, A. S. (2008). Suicidality and self-harm among sexual minorities in Japan. Qualitative Health Research, 18(10), 1429-1441.

https://doi.org/10.1177/1049732308322605

El Majzoub, I., El Khuri, C., Hajjar, K., Chebl, R. B., Talih, F., Makki, M., ... Abou Dagher, G. (2018). Characteristics of patients presenting post-suicide attempt to an Academic Medical Center Emergency Department in Lebanon. Annals of General Psychiatry, 17(1), 21.

https://doi.org/10.1186/s12991-018-0191-5

Farhood, L. F., \& Dimassi, H. (2012). Prevalence and predictors for post-traumatic stress disorder, depression and general health in a population from six villages in South Lebanon. Social Psychiatry and Psychiatric Epidemiology, 47(4), 639-649.

https://doi.org/10.1007/s00127-011-0368-6

Ghandour, L. A., \& El Sayed, D. S. (2013). Gambling behaviors among university youth: does one's religious affiliation and level of religiosity play a role? Psychology of Addictive Behaviors, 27(1), 279. https://doi.org/10.1037/a0030172

Ghandour, L. A., Karam, E. G., \& Maalouf, W. E. (2009). Lifetime alcohol use, abuse and dependence among university students in Lebanon: exploring the role of religiosity in different religious faiths. Addiction, 104, 940-948. https://doi.org/10.1111/j.1360$\underline{0443.2009 .02575 . x}$ 
Greenfield, E.A., \& Marks, N.F. (2007) Religious social identity as an explanatory factor for associations between more frequent formal religious participation and psychological wellbeing. The International Journal for the Psychology of Religion, 17(3), 245-259.

https://doi.org/10.1080/10508610701402309

Harb, C., \& Smith, P. B. (2008). Self-construals across cultures: Beyond independenceinterdependence. Journal of Cross-Cultural Psychology, 39, 178-19.

https://doi.org/10.1177/0022022107313861

Haw, C., Hawton, K., Houston, K., \& Townsend, E. (2001). Psychiatric and personality disorders in deliberate self-harm patients. The British Journal of Psychiatry, 178(1), 48-54. https://doi.org/10.1192/bjp.178.1.48

Human Rights Watch. 2018. World report, Country: Lebanon 2018, Human rights watch [Online]. https://www.hrw.org/world-report/2018/country-chapters/lebanon

Hawton, K., Rodham, K., Evans, E., \& Weatherall, R. (2002). Deliberate self-harm in adolescents: A self-report survey in schools in England. British Medical Journal, 325, 12071211. https://doi.org/10.1136/bmj.325.7374.1207

Itani, T., Fischer, F., \& Chu, J. J. (2018) The lifetime prevalence of exposure to community violence among Lebanese university students: association with behavioural and mental health correlates. International Journal of Adolescence and Youth, 23(2), 259-267.

https://doi.org/10.1080/02673843.2017.1337585

Jaspal, R., \& Breakwell, G.M. (eds) (2014). Identity Process Theory: Identity, Social Action and Social Change. Cambridge: Cambridge University Press.

https://doi.org/10.1017/CBO9781139136983

Jaspal, R., Lopes, B., \& Rehman, Z. (2019). A structural equation model for predicting depressive psychopathology in Black, Asian \& Minority Ethnic lesbian, gay \& bisexual people in the UK. Psychology and Sexuality.

https://doi.org/10.1080/19419899.2019.1690560

Karam, E. G., Mneimneh, Z. N., Dimassi, H., Fayyad, J. A., Karam, A. N., Nasser, S. C., ... Kessler, R. C. (2008) Lifetime prevalence of mental disorders in Lebanon: First onset, treatment, and exposure to war. PLoS Medicine, 5(4), e61.

https://doi.org/10.1371/journal.pmed.0050061

Karam, E. G., Mneimneh, Z. N., Karam, A. N., Fayyad, J. A., Nasser, S. C., Chatterji, S., \& Kessler, R. C. (2006). Prevalence and treatment of mental disorders in Lebanon: a national epidemiological survey. Lancet, 367(9515), 1000-1006. https://doi.org/10.1016/S01406736(06)68427-4

Kazarian, S. S. (2005) Family functioning, cultural orientation, and psychological well-being among university students in Lebanon. The Journal of Social Psychology, 145, 141-154. https://doi.org/10.3200/SOCP.145.2.141-154

Khamis, V. (2012). Impact of war, religiosity and ideology on PTSD and psychiatric disorders in adolescents from Gaza Strip and South Lebanon. Social Science \& Medicine, 74(12), 2005-2011. https://doi.org/10.1016/j.socscimed.2012.02.025

King, M., Semlyen, J., Tai, S. S., Killaspy, H., Osborn, D., Popelyuk, D., \& Nazareth, I. (2008). A systematic review of mental disorder, suicide, and deliberate self harm in lesbian, gay and bisexual people. BMC Psychiatry, 8(1), 70. https://doi.org/10.1186/1471-244X-8-70 Labaki, B., \& Abou Rjeili, K. (eds.) (1994). Bilan des Guerres du Liban: 1975-1990. Paris: L'Harmattan.

Liu, R.T., \& Mustanski, B. (2012) Suicidal ideation and self-harm in lesbian, gay, bisexual, and transgender youth. American Journal of Preventive Medicine, 42, 221-228

https://doi.org/10.1016/j.amepre.2011.10.023 
Maatouk, I., \& Jaspal, R. (2020). Religion, male bisexuality and sexual health in Lebanon. In A. K. T. Yip \& A. Toft (eds.), Bisexuality, Spirituality \& Identity (pp. 137-155). London:

Routledge https://doi.org/10.4324/9780429019913-9

Macaron, G., Fahed, M., Matar, D., Bou-Khalil, R., Kazour, F., Nehme-Chlela, D., \& Richa, S. (2014). Anxiety, depression and suicidal ideation in Lebanese patients undergoing hemodialysis. Community Mental Health Journal, 50(2), 235-238.

https://doi.org/10.1007/s10597-013-9669-4

Makarem, G. (2012). Lebanon and LGBT: The story of Helem. Europe Solidaire sans Frontières. [Online]. http://www.europe-solidaire.org

McMahon, E. M., Corcoran, P., McAuliffe, C., Keeley, H., Perry, I. J., \& Arensman, E. (2013). Mediating effects of coping style on associations between mental health factors and self-harm among adolescents. Crisis: The Journal of Crisis Intervention and Suicide Prevention, 34(4), 1-9 https://doi.org/10.1027/0227-5910/a000188

McManus, S., Bebbington, P., Jenkins, R., \& Brugha, T. (eds.) (2016). Mental health and wellbeing in England: Adult Psychiatric Morbidity Survey 2014. Leeds: NHS Digital. Marshal, M. P., Dietz, L. J., Friedman, M. S., Stall, R., Smith, H. A. (2011) Suicidality and depression disparities between sexual minority and heterosexual youth: a meta-analytic review. Journal of Adolescent Health, 49, 115-23.

https://doi.org/10.1016/j.jadohealth.2011.02.005

Meanley, S., Pingel, E. S. \& Bauermeister, J. A. (2016). Psychological well-being among religious and spiritual-identified young gay and bisexual men. Sexuality Research and Social Policy, 13, 35-45. https://doi.org/10.1007/s13178-015-0199-4

Moussa, M. M., \& Bates, G. W. (2011). A preliminary investigation of Lebanese students' strategies for coping with stressful events. Mental Health, Religion \& Culture, 14(5), 489510. https://doi.org/10.1080/13674676.2010.486779

Murtagh, N., Gatersleben, B., \& Uzzell, D. (2014). Identity threat and resistance to change: evidence and implications from transport-related behavior. In R. Jaspal and G.M. Breakwell (eds), Identity Process Theory: Identity, Social Action and Social Change (pp. 335-356). Cambridge: Cambridge University Press. https://doi.org/10.1017/CBO9781139136983.021 Mustanski, B. S., Garofalo, R., \& Emerson, E. M. (2010). Mental health disorders, psychological distress, and suicidality in a diverse sample of lesbian, gay, bisexual, and transgender youths. American Journal of Public Health, 100, 2426-32.

https://doi.org/10.2105/AJPH.2009.178319

Nauffal, D., Ammar, D., \& Sbeity, R. (2013). The role of perceived social support in predicting subjective wellbeing in Lebanese college students. The Journal of Happiness \& Well-Being, 1, 121-134. https://www.journalofhappiness.net/article/the-role-of-perceivedsocial-support-in-predicting-subjective-wellbeing-in-lebanese-college-students

Obeid, S., Haddad, C., Salame, W., Kheir, N. \& Hallit., S. (2020) Correlates of homophobic attitudes in Lebanon: Results of a cross-sectional study. Journal of Homosexuality, 67(6), 844-862. https://doi.org/10.1080/00918369.2018.1557954

Ozbay, F., Johnson, D. C., Dimoulas, E., Morgan, C. A., Charney, D., Southwick, S. (2007). Social support and resilience to stress: from neurobiology to clinical practice. Psychiatry (Edgmont), 4(5), 35-40.

Plante, T. G., Vallaeys, C. L., Sherman, A. C., \& Wallston, K. A. (2002). The development of a brief version of the Santa Clara Strength of Religious Faith Questionnaire. Pastoral Psychology, 50(5), 359-368. https://doi.org/10.1023/A:1014413720710

Rehman, Z., Lopes, B., \& Jaspal, R. (2020). Predicting self-harm in an ethnically diverse sample of lesbian, gay and bisexual people in the United Kingdom. International Journal of Social Psychiatry. https://doi.org/10.1177/0020764020908889 
Schludermann, E. H., Schludermann, S. M., Needham, D. \& Mulenga, M. (2001) Fear of rejection versus religious commitment as predictors of adjustment among reformed and Evangelical college students in Canada. Journal of Beliefs \& Values, 22(2), 209-224.

https://doi.org/10.1080/13617670120092438

Sellick, S. M., Edwardson, A. D. (2007). Screening new cancer patients for psychological distress using the hospital anxiety and depression scale. Psycho-Oncology, 16, 534-542.

https://doi.org/10.1002/pon.1085

Shuper, P. A., Neuman, M., Kanteres, F., Baliunas, D., Joharchi, N. \& Rehm, J. (2010)

Causal considerations on alcohol and HIV/AIDS-a systematic review. Alcohol, 45, 159-66.

https://doi.org/10.1093/alcalc/agp091

Skegg, K. (2005). Self-harm. The Lancet, 366(9495), 1471-1483.

https://doi.org/10.1016/S0140-6736(05)67600-3

Wehbe, H. (2011). Predictors of attitudes toward psychological counseling among Lebanese college students. Graduate Student Journal of Psychology, 13, 25-29. 
Table 1: Description of the participant sample

\begin{tabular}{|c|c|c|}
\hline & Mean & SD \\
\hline \multirow[t]{2}{*}{ Age } & 21 & 2.45 \\
\hline & $\mathbf{n}$ & $\%$ \\
\hline \multicolumn{3}{|l|}{ Gender } \\
\hline Males & 69 & 33 \\
\hline Females & 135 & 64 \\
\hline Non-binary & 5 & 2 \\
\hline \multicolumn{3}{|l|}{ Sexual Orientation } \\
\hline Heterosexual & 140 & 67 \\
\hline Bisexual & 39 & 19 \\
\hline Gay & 18 & 9 \\
\hline Lesbian & 9 & 4 \\
\hline Other & 7 & 2 \\
\hline \multicolumn{3}{|l|}{ Relationship status } \\
\hline Single & 151 & 72 \\
\hline Monogamous relationship & 52 & 25 \\
\hline Open relationship & 1 & 0.4 \\
\hline Engaged & 1 & 0.4 \\
\hline Married & 3 & 1.3 \\
\hline Civil partnership & 1 & 0.4 \\
\hline \multicolumn{3}{|l|}{ Nationality } \\
\hline Lebanese & 197 & 94 \\
\hline Palestinian & 4 & 1.9 \\
\hline Syrian & 2 & 1 \\
\hline Other arab & 6 & 2.9 \\
\hline \multicolumn{3}{|l|}{ Religion } \\
\hline Maronite & 75 & 36 \\
\hline Catholic & 29 & 14 \\
\hline Greek Orthodox & 17 & 8 \\
\hline Sunni & 40 & 19 \\
\hline Shiaa & 26 & 12 \\
\hline Druze & 12 & 6 \\
\hline Other & 10 & 5 \\
\hline
\end{tabular}


Table 2: Description of key variables of interest

\begin{tabular}{|c|c|c|}
\hline & $\mathbf{n}$ & $\%$ \\
\hline \multicolumn{3}{|l|}{ Reported self-harm } \\
\hline Yes & 106 & 51 \\
\hline \multirow[t]{2}{*}{ No } & 103 & 49 \\
\hline & Mean & SD \\
\hline \multicolumn{3}{|l|}{ Computed scores } \\
\hline Religiosity & 2.35 & 1.19 \\
\hline Identity threat & 3.0 & 0.83 \\
\hline Psychological distress & 1.8 & 0.98 \\
\hline
\end{tabular}

Table 3: Correlations between key variables of interest

\begin{tabular}{lcccc}
\hline & $\mathbf{1}$ & $\mathbf{2}$ & $\mathbf{3}$ & $\mathbf{4}$ \\
\cline { 2 - 5 } 1. Age & - & -0.126 & -0.015 & $-0.191^{*}$ \\
2. Psychological distress & -0.126 & - & $-0.241^{*}$ & $0.281^{*}$ \\
3. Religiosity & -0.015 & $-0.241^{*}$ & - & $-0.199^{*}$ \\
4. Identity threat & $-0.191^{*}$ & $0.281^{*}$ & $-0.199^{*}$ & - \\
\hline
\end{tabular}

